\section{Orthodontic Therapy}

Marian-Vladimir Fundamental Treatment Concepts

DDS, PhD

Holistic Dental \& Medical Institute of Bucharest-ROPOSTURO, Bucharest,

Romania

dr.vladimir.constantinescu@gmail.com

Authors: Herbert F. Wolf / Andrea Wichelhaus

Publisher: Georg Thieme Verlag KG, Germany

Language: English

ISBN: 978-3-13-200851-9

Edition: 1/e

Publish Year: 2018

Pages: 580, illustrated

Price: $229.00 €$

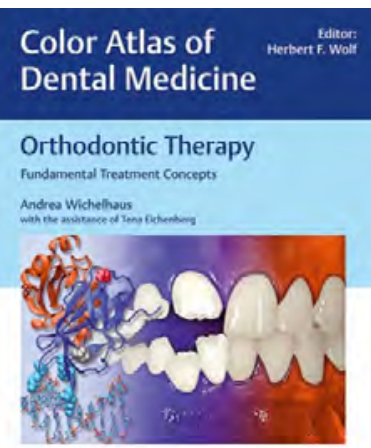

QThieme

In the series Color Atlas of Dental Medicine Drs Herbert F. Wolf and Andrea Wichelhaus present the book entitled Orthodontic Therapy discussing the diagnosis, prevention and treatment of dental and maxillary anomalies, extensively illustrated. This book is divided into 7 chapters. The fundamental problems in orthodontics, namely biomechanical factors, extrusion, intrusion, rotation, torque, force and resorption relationship, orthodontic dental movement, hereditary anomalies, genetics, mechanobiology and orthodontic side effects are the subject of the first chapter. Treatment of lateral and anterior crossbite in primary and early mixed dentition, crossbite in late mixed dentition and in adults, and treatment of laterognathia in adults, definition and therapy of deep bite in mixed and permanent dentition, orthodontic mechanics for bite raising and orthognathic surgery and deep bite are developed in Chapter 2 and 3. rthodontic problems of open bite, treatment of open bite in the primary, mixed and permanent dentition, treatment of open bite and Angle Class I, II and III, biomechanics, extraction, molar intrusion, and orthognathic surgery of open bite are described along chapter 4. Chapters 5 and 6 analyze the orthodontic treatment of Class II and III malocclusions. The chapters approach orthodontic problems, cause and differential diagnosis, treatment in the late mixed and permanent dentition, adult treatment and stability parameters. Extraction therapy is the theme of the last chapter, in which we are acquainted with extraction therapy in the early mixed and permanent dentition and in Class I, II and III anomalies and stability parameters. The book is accompanied by an index. This book is the result of many years of clinical research and practical activity and reflects the therapeutic concept of orthodontic treatment of the universities in Ulm, Basel and Munich. The book is an update of the basic principles of biology, mechanics, and biomechanics using the latest materials and techniques. It provides the reader with concepts of treatment from functional orthodontics to the integration of retained teeth, anchorage options, finishing and retention and aesthetic alternatives. The therapeutic methods are thoroughly presented and illustrated eloquently and extensively through almost 4,000 images. The book addresses experienced orthodontists and trainees as a guide, which should be present in any library.

DOI: 10.25241/stomaeduj.2018.5(2).bookreview.3 